\title{
Commentary: Some is good, so more must be better, right?
}

\author{
J. Hunter Mehaffey, MD, MSc, and Robert B. Hawkins, MD, MSc
}

From the Division of Thoracic and Cardiovascular Surgery, University of Virginia, Charlottesville, Va. Disclosures: Authors have nothing to disclose with regard to commercial support.

Received for publication June 12, 2019; accepted for publication June 13, 2019; available ahead of print July 26, 2019.

Address for reprints: J. Hunter Mehaffey, MD, MSc, University of Virginia, Charlottesville, VA 22903 (E-mail: jhm9t@virginia.edu).

J Thorac Cardiovasc Surg 2020;159:2170

$0022-5223 / \$ 36.00$

Copyright $(C) 2019$ by The American Association for Thoracic Surgery

https://doi.org/10.1016/j.jtcvs.2019.06.032

In this issue of the Journal, Angleitner and colleagues ${ }^{1}$ present an interesting retrospective study assessing unilateral versus bilateral antegrade cerebral perfusion (ACP) during surgical repair of acute type $\mathrm{A}$ aortic dissection. This single-center experience sheds light on an important clinical question, finding no overall survival benefit for bilateral ACP. In subgroup analysis, however, Angleitner and colleagues ${ }^{1}$ suggest that patients requiring longer than $50 \mathrm{mi}$ nutes of ACP have a survival benefit with a bilateral approach.

Angleitner and colleagues ${ }^{1}$ are to be commended for attempting to answer this question; however, the retrospective nature of the study is susceptible to considerable selection bias. The surgeon was allowed to decide on type of ACP used, and some of the clinical factors leading to the decision are likely not captured in a database. Two aortic specialists performed about one-third of cases, and they performed numerically more cases with bilateral ACP, in addition to a greater number of total arch replacements. In a study so limited by sample size, the effect of these differences is largely unknown. A recent Society of Thoracic Surgeons national database study found only $34 \%$ of patients were cannulated in the axillary artery, and $46 \%$ received antegrade cerebral perfusion. ${ }^{2}$ The generalizability of these findings thus may be limited. Although Angleitner and colleagues ${ }^{1}$ excluded all patients with retrograde cerebral perfusion, the national Society of Thoracic Surgeons study actually found a potential benefit of retrograde cerebral perfusion relative to $\mathrm{ACP}{ }^{2}$

The primary goal of surgical repair of acute type A aortic dissection is stabilization of the aortic root and elimination of the aortic dissection plane and ascending fenestrations to restore true lumen flow. ${ }^{3}$ There has been a trend toward increasing complexity of aortic repairs for acute type A dissection. ${ }^{4}$ This is evidenced by a move away from isolated ascending repair toward hemiarch replacement, which should still require less than 30 minutes of circulatory arrest

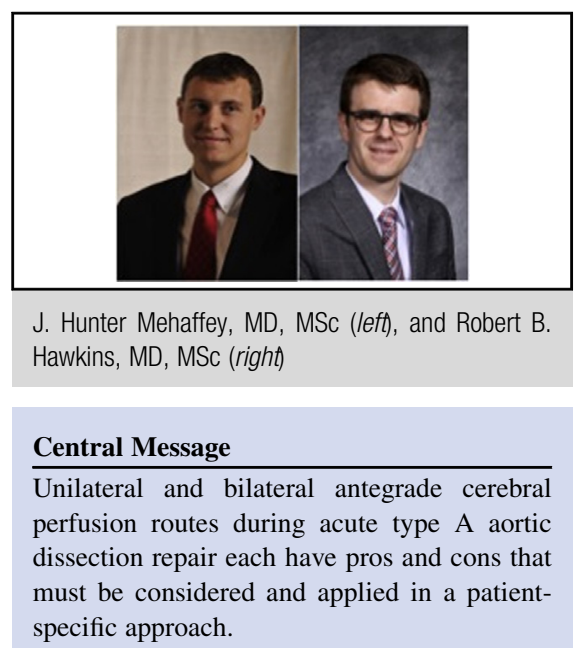

See Article page 2159.

time. There thus should be few cases requiring ACP longer than 50 minutes. Total arch or frozen elephant trunk procedures should be tailored to specific patient needs and performed by experienced aortic surgeons. These are not elective arch cases, however, and the cerebral perfusion strategy should similarly be tailored. The potential perfusion benefit should be weighed against further manipulation of dissected friable small vessels. Another scenario in which surgeons should consider expanded cerebral perfusion strategies is reoperative cardiac surgery, with anticipated longer circulatory arrest. ${ }^{5}$

\section{References}

1. Angleitner P, Stelzmueller M, Mahr S, Kaider A, Laufer G, Ehrlich M. Bilateral or unilateral antegrade cerebral perfusion during surgery for acute type A dissection. J Thorac Cardiovasc Surg. 2020;159:2159-67.e2.

2. Ghoreishi M, Sundt TM, Cameron DE, Holmes SD, Roselli EE, Pasrija C, et al. Factors associated with acute stroke after type A aortic dissection repair: an analysis of the Society of Thoracic Surgeons National Adult Cardiac Surgery Database. J Thorac Cardiovasc Surg. 2020;159:2143-54.e3.

3. Preventza O, Simpson KH, Cooley DA, Cornwell L, Bakaeen FG, Omer S, et al. Unilateral versus bilateral cerebral perfusion for acute type A aortic dissection. Ann Thorac Surg. 2015;99:80-7.

4. Hawkins RB, Mehaffey JH, Downs EA, Johnston LE, Yarboro LT, Fonner CE, et al. Regional practice patterns and outcomes of surgery for acute type A aortic dissection. Ann Thorac Surg. 2017;104:1275-81.

5. Krebs ED, Mehaffey JH, Hawkins RB, Beller JP, Fonner CE, Kiser AC, et al. Outcomes after acute type A aortic dissection in patients with prior cardiac surgery. Ann Thorac Surg. 2019;108:708-13. 